\title{
Synthesis, Characterization, and Evaluation of Adsorption Properties of Activated Carbon Obtained from Neem Leaves (Azadirachta Indica)
}

\author{
ISHTIYAK QADIR* and R. C. CHHIPA \\ Department of Chemistry, Centre for Air and Water Modalling (CAWM), Suresh Gyan \\ Vihar University, Jaipur-302017, India. \\ ${ }^{*}$ Corresponding author E-mail: scholarqadir@gmail.com \\ http://dx.doi.org/10.13005/ojc/330460
}

(Received: May 06, 2017; Accepted: June 30, 2017)

\begin{abstract}
Textile effluents are one of the main sources of severe pollution problems worldwide due to vast diversity of chemicals reagents used by textile industries for various production steps. The discharge of dye containing effluents into fresh water bodies is undesirable because of the color. In the present work, activated carbon was prepared from the leaves of Azdirachta indica (Neem) by nine different carbonization processes. The effect of $\mathrm{pH}$ on the adsorption of four classes of dyes namely acid dye (Acid blue 49), basic dye (Basic red 29), reactive dye (Reactive orange 4) \& direct dye (Direct blue 53) was studied by activated carbon $\left(\mathrm{NAC}_{2}\right.$ ), prepared from Neem leaves by $\mathrm{H}_{3} \mathrm{PO}_{4}$ impregnation method. The effect of $\mathrm{pH}$ on the adsorption of four classes of dyes is discussed and the adsorption properties of activated carbon are evaluated. Effluent samples from textile dyeing effluents were also treated using the selected activated carbon. From the present studies, it has been evaluated that the activated carbon prepared from Azadiarchta indica (Neem leaves) could be used an efficient low-cost alternative to the commercial activated carbon.
\end{abstract}

Keywords: Effluents, BOD, COD, Activated Carbon, Acid dye, Basic dye, Reactive dye \& Direct Dye

\section{INTRODUCTION}

Water is one of the most important natural resources required for the survival of life. Textile industries and their waste waters are increasing proportionally due to increased demand for textile products. Thus, textile industries are one of the main sources of severe pollution problems worldwide'.
Textile industries use more than $70 \%$ of the total quantity of dyes produced annually ${ }^{2}$. Also, vast diversity of chemicals reagents is used by textile industries for various production steps. The reagents range from polymers, inorganic and organic compounds ${ }^{3}$. The discharge of dye containing effluents into fresh water bodies is undesirable because of the color. The breakdown products 
are highly toxic, carcinogenic, or mutagenic to life forms due to presence of carcinogens including naphthalene, benzidene and other aromatic compounds ${ }^{4}$.

Textile wastewaters are also rich in recalcitrant organics, toxicants, color, chlorinated compounds \& surfactants. The synthetic dyes used include azo dyes, VAT dyes and mordents. Most of the synthetic dyes are toxic, mutagenic \& carcinogenic 5 . Mordents used for fixing of colors contain heavy metals including $\mathrm{Cr}$, $\mathrm{Fe}, \mathrm{Cu}$, and $\mathrm{Cd}$, which are highly toxic in nature.

Effluents of textiles produced and released by different production steps have high $\mathrm{pH}$, temperature, oils, detergents, dissolved solids, suspended solids, toxic metals, dispersants, leveling agents, color, alkalinity \& non-biodegradable matter ${ }^{6}$. Textile effluents are characterized by extreme fluctuation of $\mathrm{pH}$, color, biochemical oxygen demand (BOD), Chemical oxygen demand (COD) \& salinity ${ }^{7}$.

Conventional bio treatments are not effective for most of the synthetic dye stuffs due to recalcitrant nature of dyes \& complex of polyaromatic structure of dyes. Further due to reductive cleavage of azo bonds under anaerobic conditions, aromatic amines formed as metabolites are more toxic than the intact dye molecules. However, aerobic conditions are desirable because it leads to total mineralization ${ }^{8}$.

Table 1: List of carbonization processes involved in the synthesis of nine varieties of activated carbon from Azadirachta indica (Neem) leaves

\begin{tabular}{|c|c|}
\hline $\begin{array}{l}\text { Activated Carbons } \\
\text { Prepared }\end{array}$ & $\begin{array}{l}\text { Methods of } \\
\text { Preparation }\end{array}$ \\
\hline $\mathrm{NAC}_{1}$ & $\mathrm{ZnCl}_{2}$ impregnation \\
\hline $\mathrm{NAC}_{2}$ & $\mathrm{H}_{3} \mathrm{PO}_{4}$ impregnation \\
\hline $\mathrm{NAC}_{3}$ & Acid process using $\mathrm{H}_{2} \mathrm{SO}_{4}$ \\
\hline $\mathrm{NAC}_{4}$ & Acid process using $\mathrm{HCl}$ \\
\hline $\mathrm{NAC}_{5}$ & Dolomite process \\
\hline $\mathrm{NAC}_{6}$ & Direct pyrolysis \\
\hline $\mathrm{NAC}_{7}$ & $\mathrm{KOH}$ impregnation \\
\hline $\mathrm{NAC}_{8}$ & $\begin{array}{l}\text { Acid process using } \\
\mathrm{H}_{2} \mathrm{SO}_{4} \& \mathrm{H}_{2} \mathrm{O}_{2}\end{array}$ \\
\hline $\mathrm{NAC}_{9}$ & $\mathrm{Na}_{2} \mathrm{SO}_{4}$ impregnation \\
\hline
\end{tabular}

Efficiency of any physicochemical or biological treatment process greatly depends on the quality, nature, and concentration of organic compounds. Besides, due to very large water consumption, the characterization of effluents is important to determine its reuse as a safe option. Thus, due to high level of contamination in textile wastewaters, the recycling has been recommended ${ }^{9-10}$.

\section{EXPERIMENTAL}

Activated carbon was prepared from the worthless plant leaves of Azadirachta indica (Neem). Neem leaves were collected from the campus area of Suresh Gyan Vihar University, Jaipur. The leaves were washed, dried, and cut into small pieces of $2-3 \mathrm{~cm}$ size. The carbonized material was then sieved into 20-50 ATM mesh size $(300-850 \mu m)$ particles. Activated carbon was prepared from the carbonized material by nine different carbonization processes as given in table1. The properties of the carbonized material were studied as per standard methods ${ }^{11}$ used for adsorption studies. The nine varieties of Neem Activated Carbons prepared are coded as $\mathrm{NAC}_{1}$ to $\mathrm{NAC}_{9}$. The activated carbon prepared was not only low cost but also ecofriendly.

\section{RESULTS AND DISCUSSIONS}

Each of the nine varieties of activated carbons was further analyzed for various physicochemical parameters as per standard methods. The various physicochemical parameters analyzed are given in table 2. Activated carbons prepared by acid processes $\left(\mathrm{NAC}_{2}, \mathrm{NAC}_{3}, \mathrm{NAC}_{4}\right.$ and $\mathrm{NAC}_{8}$ ) were acidic with $\mathrm{pH}$ less than 7 . This is due to the introduction of acidic groups on the surfaces of activated carbon. All the remaining activated carbons were basic in nature. Most of the commercial activated carbons are basic in nature ${ }^{12}$.

The conductivity of activated carbons is due to the development of exchangeable sites on the surface of activated carbons ${ }^{12}$. The reason for moderate $(1.542 \mu \mathrm{S} / \mathrm{cm})$ and high conductivity (3.786 $\mu \mathrm{S} / \mathrm{cm})$ of $\mathrm{NAC}_{2}$ and $\mathrm{NAC}_{9}$ is due to the development of more number of exchangeable sites on the surface of activated carbons. The low conductivity of other activated carbons indicates the 
less number of exchangeable sites on the surface of activated carbon.

Activated carbons prepared by pyrolysis and $\mathrm{KOH}$ activation have moisture content of $12.51 \%$ and $11.92 \%$ respectively, which is very high. Although, there is no effect of moisture content on the adsorptive power of activated carbon but due to dilution, additional weight of activated carbon is required during treatment process ${ }^{13}$. All other carbons had moisture content almost similar to that of the commercial activated carbon. Similar results were reported by earlier researcher's also $^{14}$.

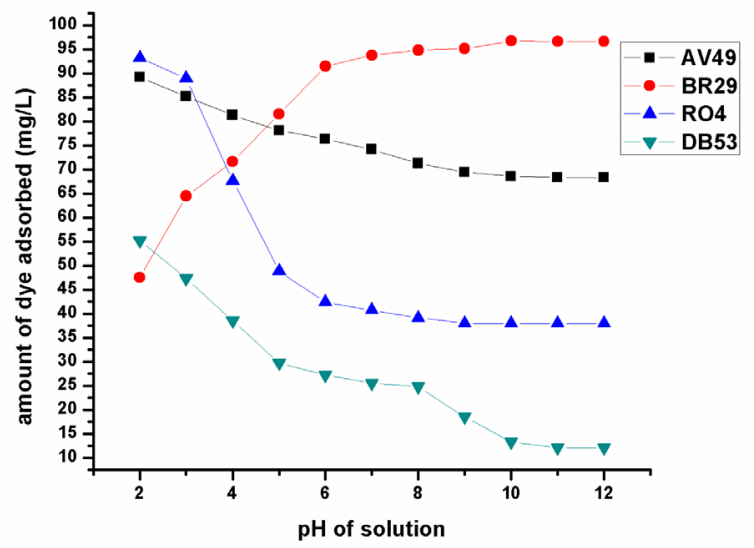

Fig 1: Effect of $\mathrm{pH}$ on the adsorption of the four selected dyes by $\mathrm{NAC}_{2}$.

Table 2: Physico-chemical Properties of Activated Carbons Prepared by Nine different Carbonization Processes from Azadirachta indica (Neem) leaves

\begin{tabular}{|c|c|c|c|c|c|c|c|c|c|}
\hline Properties & $\mathrm{NAC}_{1}$ & $\mathrm{NAC}_{2}$ & $\mathrm{NAC}_{3}$ & $\mathrm{NAC}_{4}$ & $\mathrm{NAC}_{5}$ & $\mathrm{NAC}_{6}$ & $\mathrm{NAC}_{7}$ & $\mathrm{NAC}_{8}$ & $\mathrm{NAC}_{9}$ \\
\hline $\mathrm{pH}$ & 7.21 & 6.79 & 6.23 & 6.54 & 7.20 & 8.52 & 7.82 & 6.40 & 8.02 \\
\hline Moisture (\%) & 8.23 & 9.25 & 7.87 & 11.43 & 7.32 & 12.51 & 11.92 & 9.87 & 10.61 \\
\hline Conductivity $(\mu \mathrm{S} / \mathrm{cm})$ & 0.234 & 1.542 & 0.213 & 0.502 & 0.476 & 0.792 & 0.810 & 0.911 & 3.786 \\
\hline Volatile Matter & 25.27 & 17.12 & 23.24 & 19.51 & 17.23 & 25.42 & 19.03 & 20.11 & 18.06 \\
\hline Ash (\%) & 10.21 & 09.91 & 15.72 & 11.95 & 18.15 & 13.12 & 17.01 & 12.30 & 14.67 \\
\hline $\begin{array}{l}\text { Matter Soluble } \\
\text { in Water (\%) }\end{array}$ & 0.21 & 0.43 & 0.52 & 0.32 & 0.41 & 0.72 & 1.1 & 0.73 & 0.48 \\
\hline $\begin{array}{l}\text { Matter Soluble in } \\
0.25 \mathrm{M} \mathrm{HCl}(\%)\end{array}$ & 1.35 & 1.72 & 1.49 & 1.39 & 1.29 & 1.78 & 1.51 & 1.74 & 1.66 \\
\hline Porosity (\%) & 49.7 & 50.2 & 48.9 & 49.9 & 54.2 & 47.6 & 48.2 & 47.8 & 46.7 \\
\hline $\begin{array}{l}\text { Surface Area } \\
(B E T), \mathrm{m}^{2} / \mathrm{g}\end{array}$ & 271.1 & 857.5 & 203.2 & 279.4 & 595.2 & 371.1 & 185.2 & 201.2 & 187.5 \\
\hline $\begin{array}{l}\text { Methylene Blue } \\
\text { Number (mg/g) }\end{array}$ & 77.21 & 281.5 & 80.01 & 98.23 & 201.7 & 83.1 & 92.50 & 74.20 & 80.7 \\
\hline lodine Number (mg/g) & 188.1 & 270.1 & 415.2 & 669.1 & 493.2 & 204.1 & 179 & 168 & 564 \\
\hline Phenol Number (mg/g) & 12.41 & 11.26 & 12.11 & 17.41 & 13.16 & 10.43 & 9.21 & 12.0 & 10.98 \\
\hline Sodium (mg/g) & 0.78 & 0.91 & 0.25 & 0.45 & 0.25 & 0.61 & 0.81 & 0.76 & 0.92 \\
\hline Potassium (mg/g) & 0.67 & 0.52 & 0.39 & 0.10 & 0.45 & 0.21 & 0.59 & 0.78 & 0.87 \\
\hline $\mathrm{pH}_{\mathrm{ZPC}}$ & 7.6 & 8.1 & 8.3 & 6.4 & 7.1 & 9.3 & 6.7 & 8.2 & 9.0 \\
\hline Fixed Carbon (\%) & 46.2 & 45.1 & 48.2 & 61.2 & 43.4 & 48.2 & 47.6 & 49.0 & 42.3 \\
\hline Yield (\%) & 39.9 & 57.3 & 47.1 & 54.5 & 45.2 & 46.9 & 47.3 & 52.5 & 40.1 \\
\hline
\end{tabular}


The amount of inorganic constituents present in the activated carbon indicates its ash content. $\mathrm{NAC}_{3}, \mathrm{NAC}_{5} \& \mathrm{NAC}_{7}$ have high ash content, which may be due to the incorporation of activating agents. The fixed carbon percentage is decreased due to high ash content. Less ash is produced by high charring nature of $\mathrm{H}_{2} \mathrm{SO}_{4}$ and $\mathrm{HCl}$ which ultimately results in an increase in the amount of fixed carbon. Activated carbon $\left(\mathrm{NAC}_{2}\right)$ prepared by $\mathrm{H}_{3} \mathrm{PO}_{4}$ impregnation method has least ash content, therefore it has highest percentage of fixed carbon. Solubility studies of activated carbon in acid \& water were performed to evaluate the amount of impurities present in the activated carbon prepared by different carbonization processes. It has been found that that all the activated carbons have very low level of acidand water-soluble matter. Thus, due to fewer amounts of soluble impurities in activated carbon prepared, the quality of treated water may not be affected much.

An adsorbent with high bulk density can hold more adsorbate per unit weight ${ }^{15}$. All activated carbons prepared had bulk density in a narrow range, indicating that activating agents have a least role in altering the bulk density. $\mathrm{NAC}_{2}$ prepared by $\mathrm{H}_{3} \mathrm{PO}_{4}$ impregnation has highest surface area of $857.5 \mathrm{~m}^{2} / \mathrm{g}$, which indicates that it is highly porous in nature. lodine number is correlated with the ability of an activated carbon to adsorb low molecular weight substances ${ }^{16}$. lodine number is a measure of surface area or capacity to adsorb small adsorbates because of small size of iodine molecules. For commercial carbons, lodine number ranges from 300 to 1,200 $\mathrm{mg} / \mathrm{g}$. Phenol number and Methylene blue number indicate the ability of an adsorbent to adsorb high molecular weight substances like dye molecule ${ }^{17}$. Methylene blue number of $\left(\mathrm{NAC}_{2}\right.$ and $\left.\mathrm{NAC}_{5}\right)$ is greater than 200, which indicates that the carbon is good for dye adsorption. High level of sodium or potassium can be taken as an advantage for removal of cations from wastewater by ion exchange process. Dolomite process followed by $\mathrm{H}_{3} \mathrm{PO}_{4}$ impregnation produced high yield of activated carbon.

Point of Zero Charge $\left(\mathrm{pH}_{\mathrm{zpc}}\right)$ indicates the positive or negative charge on the surface of the adsorbent. If $\mathrm{pH}$ is greater than $\mathrm{pH}_{\mathrm{zpc}}$, then the surface is negatively charged which adsorbs cations. On the other hand, if the $\mathrm{pH}$ is less than $\mathrm{pH}_{\mathrm{zPC}}$, the surface is positively charged and thus anions are adsorbed on the surface.

Based on the physicochemical properties, one of the superior activated carbons $\left(\mathrm{NAC}_{2}\right)$, prepared by $\mathrm{H}_{3} \mathrm{PO}_{4}$ impregnation was selected out of the nine varieties of activated carbons prepared for further adsorption studies.

\section{Adsorption studies of activated carbon prepared by $\mathrm{H}_{3} \mathrm{PO}_{4}$ impregnation}

The adsorption properties of activated carbon prepared by $\mathrm{H}_{3} \mathrm{PO}_{4}$ impregnation method was studied by four classes of dyes namely acid dye (Acid blue 49), basic dye (Basic red 29), reactive dye (Reactive orange 4) and direct dye (Direct blue 53) through batch adsorption studies. In the present studies, the effect of $\mathrm{pH}$ on the adsorption of four classes of dyes is discussed \& the adsorption

Table 3: Effect of $\mathrm{pH}$ on the adsorption of four selected dyes by $\mathrm{NAC}_{2}$

\begin{tabular}{ccccc}
\hline $\mathbf{p H}$ & $\begin{array}{c}\text { Acid Violet 49 } \\
\text { (AV49), } \mathbf{~ m g / g}\end{array}$ & $\begin{array}{c}\text { Basic Red 29 } \\
\text { (BR29), } \mathbf{~ m g / g}\end{array}$ & $\begin{array}{c}\text { Reactive Orange 4 } \\
\text { (RO4), } \mathbf{~ m g / g}\end{array}$ & $\begin{array}{c}\text { Direct Blue 53 } \\
\text { (DB53), } \mathbf{~ m g / g}\end{array}$ \\
\hline 2 & 89.21 & 47.51 & 93.21 & 55.23 \\
3 & 85.16 & 64.45 & 88.96 & 47.31 \\
4 & 81.32 & 71.63 & 67.65 & 38.53 \\
5 & 78.12 & 81.52 & 48.83 & 29.71 \\
6 & 76.31 & 91.43 & 42.42 & 27.21 \\
7 & 74.16 & 93.76 & 40.72 & 25.56 \\
8 & 71.23 & 94.79 & 39.11 & 24.79 \\
9 & 69.42 & 95.12 & 38.01 & 18.52 \\
10 & 68.56 & 96.72 & 38.01 & 13.33 \\
11 & 68.32 & 96.63 & 38.01 & 12.12 \\
12 & 68.32 & 96.63 & 38.01 & 12.12 \\
\hline
\end{tabular}


properties of activated carbon are evaluated. Effluent samples from textile dyeing effluents were also treated using the selected activated carbon. From the present studies, it has been evaluated that the activated carbon prepared from Azadiarchta indica (Neem leaves) could be used an efficient low-cost adsorbent as compared to the commercial activated carbon.

The used dyes were separately dissolved in $1000 \mathrm{ml}$ of distilled water to prepare stock solutions of $1000 \mathrm{mg} / \mathrm{L}$ of each adsorbate. Appropriate concentrations of the stock solution were obtained by diluting it with distilled water as and required.

\section{Effect of $\mathrm{pH}$ on the adsorption of dyes by activated carbon}

$\mathrm{pH}$ is an important factor which influences the solution chemistry of dyes, complexation by organic or inorganic ligands, precipitation, hydrolysis, and redox reactions. $\mathrm{pH}$ also influences the speciation and availability of dyes for adsorption ${ }^{18}$. Table 3 represents the data for the $\mathrm{pH}$ range of 2 to 12 for the adsorption of four selected dyes on $\mathrm{NAC}_{2}$ and the fig1 represents the effect of $\mathrm{pH}$ on the adsorption of the selected dyes.

Adsorption of dyes by activated carbon depends on the electrostatic interaction between surface of adsorbent and adsorbate. It has been found that $\mathrm{pH}$ largely affects the uptake of cationic and anionic dyes. From the given data, it can be seen that uptake of cationic dyes increases whereas that of anionic dyes decreases for the $\mathrm{pH}$ range of 2 to 12. Similar results were obtained from the adsorption properties of activated carbon obtained from Euphorbia antiquorum wood ${ }^{19}$.

\section{Effect of $\mathrm{pH}$ on the adsorption of Acid Violet 49 (AV49):}

When $\mathrm{pH}$ was increased from 2 to 12 , the uptake of AV49 decreased from 89.21 to $68.32 \mathrm{mg} / \mathrm{g}$. The dye showed maximum adsorption at $\mathrm{pH} 2$. When the $\mathrm{pH}$ of solution is increased above 3.2, there is a reduction in the amount of dye adsorbed due to repulsion between adsorbent and adsorbate surface. Above $\mathrm{pH}$ of 3.2, the dye exists in ionic form. It has been found earlier that the adsorption capacity of any solute molecule is more in molecular form than its ionic form ${ }^{20}$.

\section{Effect of pH on the adsorption of Basic Red 29 (BR29)}

On increasing the $\mathrm{pH}$ of solution from 2 to 12 , the uptake of BR29 increased from 47.51 to $96.63 \mathrm{mg} / \mathrm{g}$, after which it remained constant. BR29 is a cationic dye. With increase in $\mathrm{pH}$, the number of negatively charged sites on activated carbon

Table 4: Physico-chemical Characteristics of treated Dyed Textile Effluents by Activated Carbon $\left(\mathrm{NAC}_{2}\right.$ ) obtained from Neem Leaves (Azadirachta indica)

\begin{tabular}{lcccccccccc}
\hline $\begin{array}{l}\text { Properties of } \\
\text { Textile Effluents }\end{array}$ & TES1 & \multicolumn{3}{c}{ TES2 } & \multicolumn{2}{c}{ TES3 } & \multicolumn{2}{c}{ TES4 } & \multicolumn{3}{c}{ TES5 } \\
\cline { 2 - 11 } & BA & AFA & BA & AFA & BA & AFA & BA & AFA & BA & AFA \\
\hline Color & $\begin{array}{c}\text { Bluish } \\
\text { Black }\end{array}$ & Nil & $\begin{array}{c}\text { Light } \\
\text { Purple }\end{array}$ & Nil & $\begin{array}{c}\text { Violet } \\
\text { Blue }\end{array}$ & $\begin{array}{c}\text { Mild } \\
\text { Violet }\end{array}$ & Green & Nil & Pink & Nil \\
& & & & & & & & & \\
\hline pH & 8.91 & 8.01 & 9.21 & 8.91 & 9.25 & 9.12 & 8.95 & 8.42 & 9.85 & 9.35 \\
TDS $(\mathrm{mg} / \mathrm{l})$ & 2733 & 1283 & 7527 & 4121 & 6834 & 2871 & 5622 & 2516 & 7947 & 3252 \\
E.C $(\mu \mathrm{S} / \mathrm{cm})$ & 4766 & 2424 & 6527 & 4311 & 5331 & 3110 & 5622 & 2591 & 6312 & 2792 \\
Alkalinity $(\mathrm{mg} / \mathrm{l})$ & 849 & 642 & 678 & 321 & 985 & 612 & 403 & 262 & 778 & 431 \\
Chloride $(\mathrm{mg} / \mathrm{l})$ & 276 & 126 & 576 & 231 & 648 & 413 & 541 & 337 & 495 & 285 \\
& & & & & & & & & & \\
Sulphate $(\mathrm{mg} / \mathrm{l})$ & 443 & 256 & 741 & 441 & 431 & 218 & 676 & 436 & 712 & 326 \\
BOD $(\mathrm{mg} / \mathrm{l})$ & 293.2 & 12 & 412.2 & 14 & 341.3 & 8 & 363.8 & 9 & 589.1 & 18 \\
COD $(\mathrm{mg} / \mathrm{l})$ & 641.4 & 25 & 870.9 & 50 & 763.23 & 45 & 782.5 & 48 & 910.2 & 58 \\
Hardness $(\mathrm{mg} / \mathrm{l})$ & 1051 & 329 & 1195 & 398 & 1121 & 473 & 1085 & 501 & 1098 & 321 \\
\hline
\end{tabular}

BA- Before Adsorption; AFA- After Adsorption; TES- Textile Effluent Sample 
increased ${ }^{21}$. The electrostatic attraction between the cationic dye molecules and negative surface of carbon increased with increase in $\mathrm{pH} \&$ reached saturation at $\mathrm{pH}$ 9. Similar results were obtained for the adsorption of BR41 by silkworm pupa ${ }^{22}$.

\section{Effect of $\mathrm{pH}$ on the adsorption of Reactive orange 4 (RO4):}

With an increase in $\mathrm{pH}$ of solution from 2 to 12 , the uptake of RO4 decreased from 93.21 to $38.01 \mathrm{mg} / \mathrm{g}$. Reactive dyes exist as anions in ionized form in aqueous solution due to the presence of sulphonate groups in them. The uptake of dye is high at low pH due to electrostatic attraction between negatively charged $\mathrm{RO} 4$ dyes and positively charged adsorbents. Also, with an increase in $\mathrm{pH}$, the number of negatively charged sites increase and those of positively charged sites decrease. Due to electrostatic repulsion, the negatively charged sites on the surface of adsorbents do not favor the adsorption of anionic dyes ${ }^{23}$.

\section{Effect of pH on the adsorption of Direct Blue 53 (DB53):}

The adsorption of DB53 decreased from 55.23 to $12.12 \mathrm{mg} / \mathrm{g}$ on increasing the $\mathrm{pH}$ from 2 to 12 . Due to hydrophobic nature of carbon, it adsorbs $\mathrm{H}^{+}$ion on its surface, thus it attains the positive charge. At low $\mathrm{pH}$, the concentration of hydrogen ions is high, thus activated carbon exists as positively charged. The electrostatic attraction between positively charged carbon and negatively charged DB53 dye causes an increase in adsorption.
As the $\mathrm{pH}$ of solution is increased, the number of negatively charged sites on activated carbon increased, which results in an increased repulsion between negatively charged activated carbon and anionic DB53 molecules. Thus, the adsorption of DB53 is decreased significantly.

Maximum adsorption was observed at $\mathrm{pH} 2$, whereas least adsorption was observed at $\mathrm{pH}$ 9. Presence of excessive $\mathrm{OH}^{-}$ions under alkaline conditions also causes a decreased adsorption of DB53 molecules due to increase in the negative sites on the surface of activated carbon.

\section{Adsorption studies of Textile Effluents of Sitapura Jaipur}

The effluent samples were collected from the outlets of textile industries. The effluent samples were treated with $\mathrm{NAC}_{2}$. The properties of treated \& untreated effluents of textile industries are given in table 4 and the fig 2 shows the graphical representation of treated effluents.

All effluents samples were colored \& turbid. Th samples were treated with Neem activated carbon $\left(\mathrm{NAC}_{2}\right.$ ), prepared by $\mathrm{H}_{3} \mathrm{PO}_{4}$ impregnation method which resulted in huge reduction of color of effluent samples. The percentage decrease in optical density and COD were taken as the reduction in the total dye concentration and the measure of total organic content respectively ${ }^{24}$.

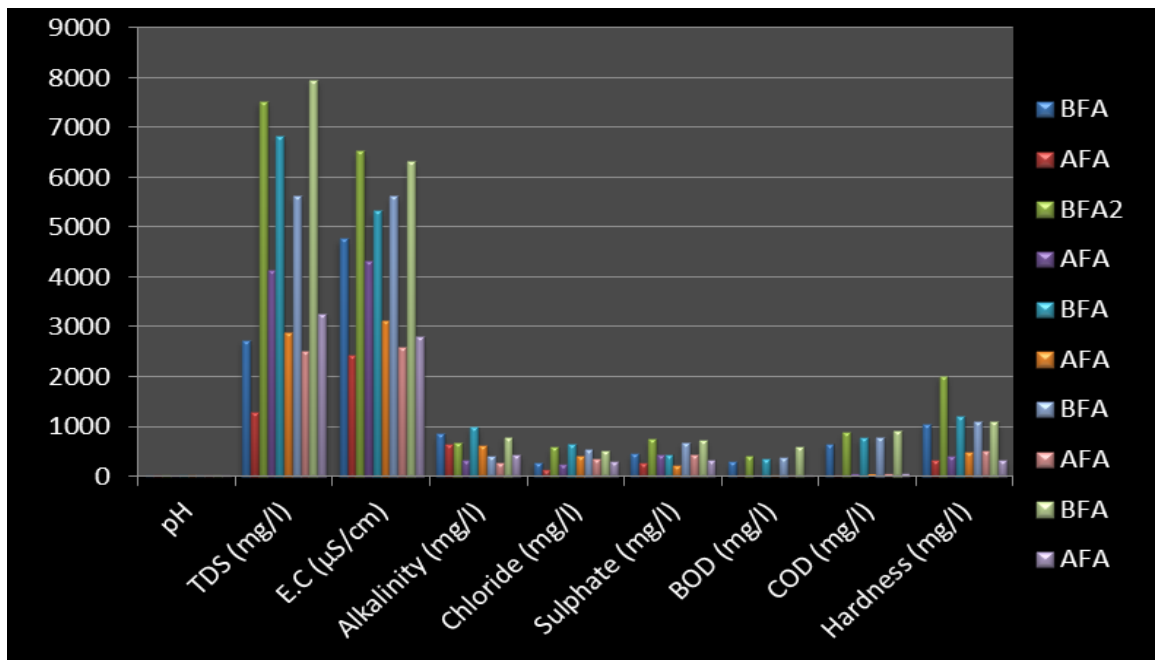

Fig 2: Properties of Textile industry effluents before and after adsorption treatment by $\mathrm{NAC}_{2}$ 
Complete color removal was observed from most samples by $\mathrm{NAC}_{2}$. Adsorption of dyes by activated carbon is dependent on several factors including TDS. High level of TDS indicates the increase in ionic strength due to the dissolved salts. High ionic strength affects the adsorption capacity of activated carbon due to the increased competition between similar ions ${ }^{25}$. The decrease in BOD \& COD is an indicator of percentage of color removal.

The nature of dye also plays an important role in the color removal by adsorption. Generally direct and reactive dyes are little reluctant towards adsorption by activated carbon. In terms of color, the pink, violet and black dyes are mostly more reluctant towards adsorption. The $\mathrm{pH}$ of the textile effluents was found to be appreciably closer to that of the ground water. Similarly, chlorides and sulphates were also removed effectively by the activated carbon. For most of the samples, the amount of $\mathrm{NAC}_{2}$ required was almost similar to that of the commercial activated carbon, which suggests that $\mathrm{NAC}_{2}$ could be used as a potential low-cost adsorbent and could serve as a better alternative to the commercial activated carbon.

\section{CONCLUSION}

Due to the extreme levels of contamination in the effluents of textile industries in various dyeing and finishing processes, the recycling of dyed textile effluents has been recommended before discharge into fresh water bodies. Textile effluents are characterized by extreme fluctuations of various parameters including $\mathrm{pH}, \mathrm{BOD}$ and $\mathrm{COD}$. The dyed textile effluents also need to be treated for azo dyes \& recalcitrant organic pollutants which are carcinogenic in nature. Adsorption of dyes by activated carbon is one of the most important and convenient techniques in vogue to remove dyes and other toxic chemicals from dyed textile effluents. The dyed textile effluent samples collected from the outlets of textile industries were treated with activated carbon $\left(\mathrm{NAC}_{2}\right)$ prepared by $\mathrm{H}_{3} \mathrm{PO}_{4}$ impregnation method from the leaves of Azadirachta indica (Neem). Complete color removal was observed in case of bluish black, light purple, green and pink colored effluent samples. However, violet samples were slightly reluctant towards the color removal. Also, the adsorption properties of activated carbon $\left(\mathrm{NAC}_{2}\right)$ were evaluated by studying the effect of $\mathrm{pH}$ on the adsorption of four classes of dyes namely AV49, BR29, RO4 \& DB53 by NAC . Further, it has been evaluated that activated carbon $\left(\mathrm{NAC}_{2}\right.$ ) obtained from Neem leaves could be used as an effective low cost alternative to the commercial activated carbon.

\section{ACKNOWLEDGEMENT}

I am highly thankful to Dr. R C Chhipa for guiding me throughout the research process at SGVU, Jaipur. I equally acknowledge my brothers Wasim Qadir, Raouf Qadir, Mohd. Ayoub and my beloved uncle for providing me the necessary support and encouragement for carrying out the research process. I also express my gratitude to Dr. Nisar Ahmed Farhad for providing me the technical support at USIC, University of Kashmir.

\section{REFERENCES}

1. Andre, B. S.; Francisco, J. C.; Jules, B. L. Bioresource Technol. 2007, 98, 2369.

2. Correia, V.M.; Stephenson T and Judd SJ, Environ Technol. 1994, 15, 917.

3. APHA.; Standard methods for the examination of water and wastewater, 20th edn. DC, New York. 1998.

4. Mishra, G.; Tripathy, M.; Colourage. 1993, 40, 35.

5. Kumar, P.; Prasad, B.; Mishra, IM.; Chand, S. J. Hazard. Mater. 2007, 149, 26.

6. Robinson.; Mcmullan, G.; Marchant, R.;
Ningam, P. Biores. Technol. 2011, 77, 247.

7. Talarposhti, AM.; Donnelly, T.; Anderson, GK. Water Res. 2001, 35, 425.

8. Bannat, IM.; Nigam, P.; Singh, D.; Marchant. Bioresource Technol. 1996, 58, 217.

9. Suteu, D.; Zaharia, C.; Bibla, D.; Muresan, A.; Muresan, R.; Popescu, A.; Industria Textila. 2009, 5, 254.

10. Varunprasath, K.; Daniel, AN.; Iranica J. Energy Environ. 2010, 1, 315.

11. ISI., "Methods of sampling and tests for activated carbon used for decolourizing 
vegetable oils and sugar solutions", Indian Standards Institute. 1977, IS-877.

12. Regnaraj, S.; Banumathi, Arabindo.; Murugesan, V. Int. J. Chem. Technol. 1999, 6, 1.

13. Karthikeyan, S.; Sivakumar, P.; Palanisamy, P.N. E.J. Chem. 2008, 5, 409.

14. Banat, I M.; Nigam P.; Singh, D.; Marchant, R. Bioresource Technol. 1996, 58, 217.

15. Malik, P.K. Dyes Pigments. 2003, 56, 239.

16. Chandrashekhar, S.; Parmada, P.N.; Adsorption. 2006, 12, 27.

17. Ekpete, O.A.; Horsfall, R. Res. J. Chem. Sci. 2011, 1, 10.

18. Ozacar, M.; Sengil, A.I.; J. Hazard. Mater.
2003, B98, 211.

19. Palanisamy, P.N.; Sivakumar, P. Rasayan J. Chem. 2008, 1, 901.

20. Nouri, S.; Hagsheresht, F.; Max, GQ. Adsorption. 2002, 8, 215.

21. Rao, M.; Bhole, A.G. Indian Chem. Eng. 2002, 44, 25.

22. Noroozi, B.; Sorial, G. A.; Bahrami H.; Arami M. J. Hazard Mater. 2007, B139, 167.

23. Won, S. W.; Wu, G.; Ma, H.; Liu, Q.; Yan, Y.; Cui, L. J. Hazard. Mater. 2006, 138, 370.

24. Prakash, A.; Solanki, A.; Prasada Rao. Indian J. Chem. Technol. 2008, 15, 146.

25. Weber, W. J.; Morris, J.C. Proc. Int. Conf. Advances in Water Poll. Res. 1963, 2, 231. 